\title{
Assessment of nasal obstruction by subjective methods and peak nasal inspiratory flow in children and adolescents with chronic rhinitis
}

\author{
Pilar Visconti, M.D. ${ }^{a}$, Ricardo J. Saranz, M.D. ${ }^{a}$, Natalia A. Lozano, M.D. ${ }^{a}$, \\ Graciela Alegre, M.D. ${ }^{a}$, Paula Robredo, M.D. ${ }^{a}$, Mariana Sacco Ramello, M.D. ${ }^{a}$, \\ Laura V. Sasia, M.D. ${ }^{a}$ and Alejandro Lozano, M.D., Ph.D. ${ }^{a}$
}

a. Division of Allergy and Immunology,

Clínica Universitaria Reina Fabiola,

School of

Health Sciences,

Universidad

Católica de

Córdoba, Córdoba,

Argentina.

E-mail address:

Ricardo J. Saranz, M.D.:

rsaranz@arnet.com.ar

Funding:

Secretary of

Technological Liaison and Research of

Universidad Católica

de Córdoba.

Conflict of interest:

None.

Received: 12-21-2020

Accepted: 3-10-2021

\begin{abstract}
Introduction. Nasal obstruction (NO) is the most irritating symptom of chronic rhinitis (CR). The results of studies that correlated subjective and objective methods of NO in children and adults were contradictory.

Objectives. To analyze the correlation between subjective NO scales and peak nasal inspiratory flow (PNIF) measurements and compare the subjective NO assessment and PNIF in children by age.

Population and methods. Participants were patients with CR. The correlation between the subjective NO assessment using a visual analog scale (NO-VAS) and the Nasal Obstruction Symptom Evaluation (NOSE) and nasal airflow measurement pre- and post-vasoconstrictor administration using the PNIF was estimated. The differences in the subjective $\mathrm{NO}$ assessment and PNIF between children aged 8-11 years and 12-15 years were analyzed.

Results. A total of 79 patients aged 8-15 years were included. No correlation was established between the NO-VAS and the PNIF before and after vasoconstrictor administration $(\mathrm{r}=-0.19$; $p=0.11$ and $\mathrm{r}=-0.18 ; p=0.15$ respectively) or between the NOSE and the baseline PNIF $(\mathrm{r}=-0.23 ; p=0.07)$. Differences were observed in the PNIF between children aged 8-11 years and $12-15$ years $(p=<0.0001)$, but there were no differences in the subjective perception assessed with the NO-VAS ( $p=0.7591)$.

Conclusion. No correlation was demonstrated between the subjective NO score and the PNIF in children and adolescents with CR. Older children have a lower perception of NO than younger ones. Subjective NO scales cannot replace the PNIF measurement in patients with rhinitis.

Key words: nasal diseases, visual analog scale, nasal obstruction, quality of life, diagnosis.
\end{abstract}

http: / / dx.doi.org/10.5546/aap.2021.eng.331

To cite: Visconti P, Saranz RJ, Lozano NA, Alegre G, et al. Assessment of nasal obstruction by subjective methods and peak nasal inspiratory flow in children and adolescents with chronic rhinitis. Arch Argent Pediatr 2021;119(5):331-338.

\section{INTRODUCTION}

Rhinitis has a great impact on the quality of life. In relation to rhinitis symptoms, nasal obstruction $(\mathrm{NO})$, described as the perception of a limited air passage through the nose, is one of the most irritating symptoms and should be included in the differential diagnosis of potential inflammatory, mechanical, and functional causes of chronic rhinitis (CR). ${ }^{1}$

The subjective and objective assessment of nasal airways may be useful for both the clinical assessment of NO from different causes and the follow-up of surgical and / or medical therapy and for the performance of nasal allergen challenge tests and the study of nasal pathophysiology and its impact on lung function. ${ }^{2-4}$

Subjective methods, such as a $\mathrm{NO}$ visual analog scale (NO-VAS) and the Nasal Obstruction Symptom Evaluation (NOSE), are simple instruments that help rhinitis patients to assess their perception of $\mathrm{NO}$ severity. 5,6 The NOSE, which is more specific than the NO-VAS, includes 5 questions about $\mathrm{NO}$ to be answered by the patient. For both the NO-VAS and the NOSE, a higher score means a greater symptom severity.

In relation to the objective assessment of nasal respiratory mechanical resistance, active anterior rhinomanometry (AAR) and acoustic rhinometry (AR) are highly sensitive and specific exploratory methods; however, the complex equipment and time required and the need of a trained operator to perform these 
tests limit their use in routine clinical practice., ${ }^{2,4}$ Although peak nasal inspiratory flow (PNIF) requires an adequate patient education to obtain reproducible results, it is a simple, fast, and inexpensive method performed using a nasal airflow measurement device in the outpatient setting. $2,7,8$

There is a growing consensus that, for an adequate diagnosis and therapeutic management, NO requires an objective assessment. ${ }^{4}$ Notwithstanding this, NO should be considered a multifactorial concept that encompasses physical, psycho-emotional, and social patient conditions; for this reason, experts suggest that symptom assessment should be approached from a comprehensive perspective, including also quality of life measurement scales such as the NOSE and VAS. ${ }^{2,4}$

The studies that correlated subjective scales and objective methods to measure NO in apparently healthy adults, ${ }^{9}$ patients with septoplasty ${ }_{10}^{10}$ patients with chronic rhinitis, ${ }^{7,11}$ and patients with chronic rhinosinusitis with polyps and deviated septum, ${ }^{12}$ and studies that included the pediatric population with rhinitis ${ }^{13-15}$ showed contradictory outcomes. Therefore, our objective was to analyze the correlation between subjective NO scales and PNIF values in children and adolescents with chronic rhinitis, and to compare the subjective assessment of $\mathrm{NO}$ in relation to PNIF in children based on their age.

\section{POPULATION AND METHODS}

This study had a prospective, observational, and analytical design and consecutively included male and female children and adolescents who sought specialized care at the Division of Allergy and Immunology between March $1^{\text {st }}, 2019$ and March 1 $1^{\text {st, }}, 2020$ and who had a diagnosis of allergic and non-allergic chronic rhinitis established by the presence of typical nasal symptoms (rhinorrhea, obstruction, pruritus, and sneezing) and the result of aeroallergen prick testing. ${ }^{16,17}$ Patients were grouped by age into 2 categories: 8 to 11 years and 12 to 15 years.

Sample size: Based on the number of first-time visits per year to the Division of Allergy and Immunology of our facility, the sample size (n) was estimated at a minimum of 68 patients with a $90 \%$ confidence and a $90 \%$ power.

Patients with the following clinical conditions were excluded:

a. Acute or chronic infection of the upper respiratory tract. b. Anatomical alterations of the nose, adenoid hypertrophy, nasal polyps.

c. History of allergen-specific immunotherapy.

d. Administration of topical or systemic steroids, antihistamines, leukotriene antagonists, and alpha-adrenergic antagonists (topical or systemic) in the past 4 weeks.

e. Active smokers and/or people exposed to cigarette smoke in their family environment.

The following outcome measures were taken from the medical records: age, sex, body mass index (BMI), duration of rhinitis, and percentage of life affected by rhinitis (based on the following equation: [age at diagnosis - age at onset/age at diagnosis] $\times 100$ ).

A standardized panel was used for allergen prick tests with the following allergens from Alergo-Pharma ${ }^{\circledR}$ : mites (Dermatophagoides pteronyssinus, D. farinae, Blomia tropicalis), environmental fungi (Alternaria sp, Aspergillus sp, Cladosporium, Mucor, Rhizopus, Penicillium), dog epithelium, cat epithelium, mix of tree, grass, and compound pollens, phenol-containing saline solution (negative control), and histamine $1 \mathrm{mg} / \mathrm{mL}$ (positive control). Tests were performed in the anterior side of the forearm with a Pricker lancet (Diater Laboratorios ${ }^{\circledR}$ ), with results obtained at 15 minutes using a millimeter graduated ruler. Results were considered positive if orthogonal diameter reading showed the presence of a papule of 3 millimeters or more in average. ${ }^{17}$

Subjective scales for the measurement of nasal obstruction: The NOSE and NO-VAS scales were used. The NOSE scale, validated and adapted to the Spanish language ${ }^{18}$ consisted of 5 items (nasal congestion, nasal blockage or obstruction, trouble breathing through the nose, trouble sleeping, and unable to get enough air through the nose during exercise or exertion) which the patient had to answer regarding the past month prior to the study. For each item, a 5-point Likert scale was used with a raw score multiplied by 5 for a total score from 0 to 100 points. A higher score implied worse NO symptoms.

The NO-VAS was scored as a horizontal, $10-\mathrm{cm}$ line, with a vertical line marked where the patient perceived symptom severity based on a $0-10$ scale. ${ }^{4}$ The left end (0) indicated the absence of $\mathrm{NO}$ and the right end (10), the worst NO severity. The physician measured the NOVAS prior to performing the PNIF and after the vasoconstrictor response.

Nasal airflow was measured using the InCheck Nasal ${ }^{\circledR}$ inspiratory flow meter (Clement 
Clark International Limited, Scotland, UK), which allowed to make a simple measurement of airflow penetrating the nasal cavities during a rapid, forced inspiration through the nose. ${ }^{7}$ Measurement was done using a scale that ranges from 30 to 370 liters / minute as indicated in the device's cylinder. The device was sterilized before each use and 3 consecutive measurements were done with a 1-minute interval (to assess reproducibility); the best performance was immediately taken as the definite reading. The results were translated into a Z-score, considering normal values for age and sex as reference, as proposed by Papachristou et al. ${ }^{19}$

After the baseline PNIF measurement, a vasoconstrictor test was done by spraying oxymetazoline $0.05 \%$ in each nasal cavity. The PNIF and the NO-VAS were repeated 15 minutes later. Nasal obstruction reversibility was estimated using the nasal congestion index $(\mathrm{NCI})=([$ PNIF post-vasoconstrictor-baseline $\mathrm{PNIF}] /$ baseline PNIF) $\times 100 .{ }^{20}$

In all cases, the allergen prick tests, VAS, NOSE, and PNIF pre- and post-vasoconstrictor administration measurements were performed by different operators, who were blinded to the other studied outcome measures. The flowchart of the study was established as shown in Figure 1.

Statistical analysis: The InfoStat ${ }^{\circledR 21}$ and R-Medic ${ }^{\circledR 22}$ statistical software programs were used to perform descriptive statistics and Spearman's correlation was done to correlate the subjective scales and the PNIF. In addition, the differences between the 8-11-years and 12-15-years age groups were analyzed using Student's $t$ test, Wilcoxon's test or the $\chi^{2}$ test, as applicable. The level of significance was set at $5 \%$.

\section{Ethical considerations}

This study is part of the research project titled "Assessment of respiratory allergic disease: The airway unit concept", approved by the Institutional Ethics Committee in Health Research (Comité Institucional de Ética en Investigación en Salud, CIEIS) of Clínica Universitaria Reina Fabiola (registered under no. 17/2013). The study was carried out in compliance with the regulations of the Declaration of Helsinki and good clinical practice, and in accordance with Law no. 9694 of the province of Córdoba (Argentina) for research on human beings. An informed consent was obtained for the performance of all interventions and data use, and confidentiality

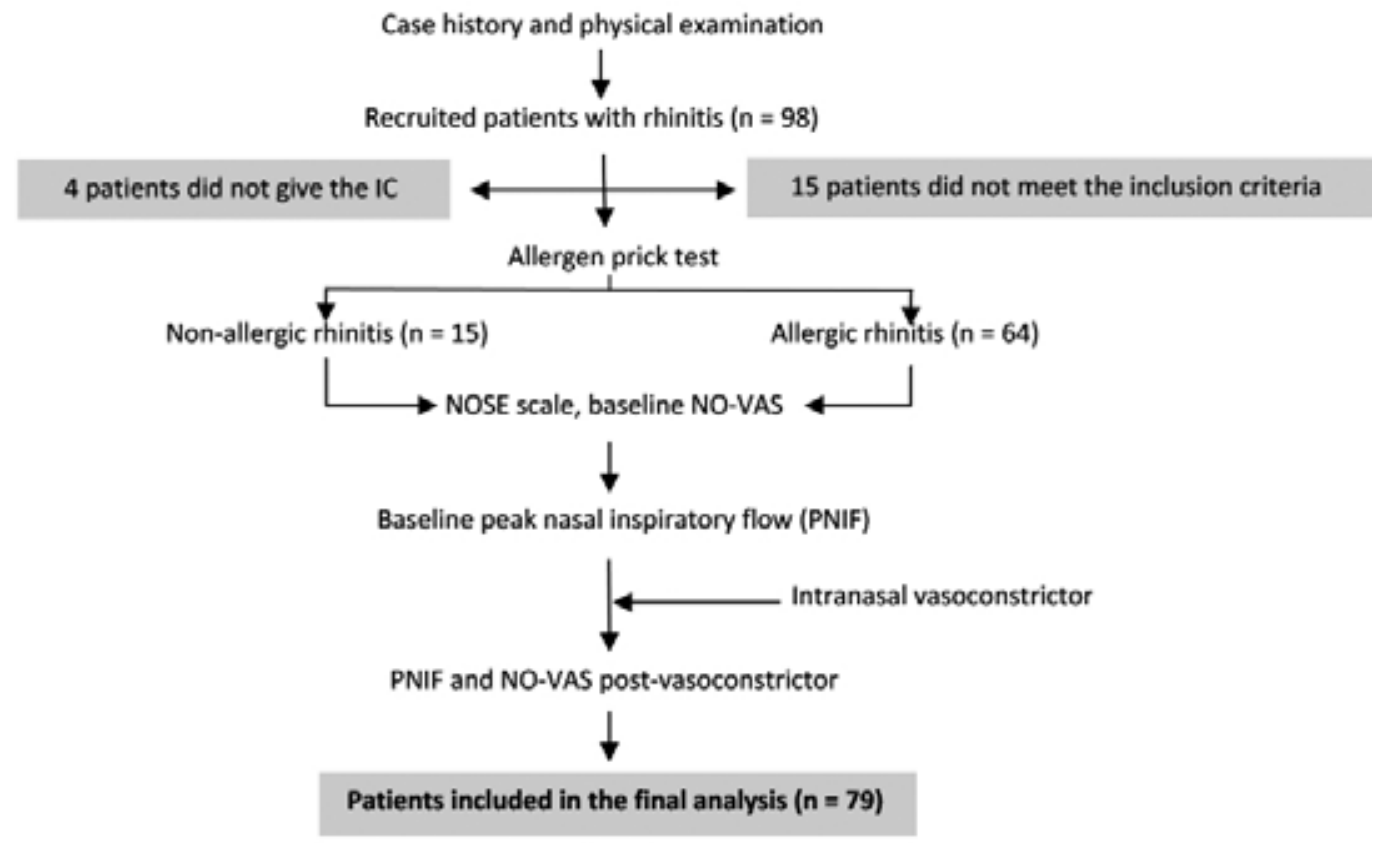

IC: informed consent, NOSE: Nasal Obstruction Symptom Evaluation, NO-VAS: nasal obstruction visual analog scale. 
was warranted in compliance with Law no. 25326 for the Protection of Personal Information.

\section{RESULTS}

A total of 98 patients with chronic rhinitis were recruited; of these, 15 were excluded because they did not meet the inclusion criteria and 4 did not give their informed consent. Finally, 79 children and adolescents (males $n=41$ ) aged 8-15 years (mean: 11.9; $\mathrm{SD} \pm 2.56$ years) were included. Their characteristics are shown in Table 1. No correlation was established between the NO-VAS and the PNIF before and after vasoconstrictor administration $(\mathrm{r}=-0.19 ; p=0.11$ and $\mathrm{r}=-0.18$; $p=0.15$ respectively) (Figures 2 and 3 ). Also, no correlation was observed between the NOSE and the baseline PNIF $(r=-0.23 ; p=0.07)$. Differences were noted in the extent of nasal obstruction established by the PNIF between children aged 8-11 years and $12-15$ years $(p=<0.0001)$, but no differences were observed in the subjective perception established by the NO-VAS estimated at the same time $(p=0.7591)$ (Figure $4, A$ and $B)$.

\section{DISCUSSION}

Rhinitis is one of the most common chronic conditions, resulting in a high health expenditure and a negative impact on the quality of life.,16 NO secondary to chronic inflammation, vasodilation, and nasal mucosa edema is the most uncomfortable symptom and the main cause of sleep problems and poor cognitive and school performance in children. ${ }^{23}$

NO poses a complex assessment in children because the stage of development and age may affect the subjective perception of the symptom. Besides, a clinical examination by a physician is difficult and hardly reproducible., ${ }^{2,4}$

Subjective scales have been considered for the assessment of NO in children and adults. ${ }^{4}$ Among these, NO-VAS is an easy, non-specific scale, whereas the NOSE, which has been validated in Spanish language, is an abridged, more specific instrument for the subjective assessment of NO. ${ }^{18}$

Authors have suggested supplementary methods for the objective measurement of NO, such as AAR, AR, and PNIF. ${ }^{4}$ Of these, the PNIF is a simple, inexpensive, reproducible, and noninvasive method to objectively measure nasal airflow in routine outpatient care. ${ }^{2}$

The correlation between subjective scales and objective methods, mainly rhinomanometry, has been studied mostly in adults with varying diseases leading to NO., ${ }^{79-12}$ However, in children

TABLE 1. Characteristics of patients with chronic rhinitis included in the study

\begin{tabular}{|c|c|c|c|}
\hline Outcome measure & Group aged 8-11 years $(N=45)$ & Group aged $12-15$ years $(N=34)$ & $p$ value \\
\hline Males (n, \%) & $25(55.56)$ & $16(47.06)$ & 0.6 \\
\hline Body mass index $\left(\mathrm{kg} / \mathrm{m}^{2}\right)^{*}$ & $\begin{array}{c}18.44 \pm 3.59 \\
(12.57 \text { to } 29.51)\end{array}$ & $\begin{array}{c}20.57 \pm 3.42 \\
(14.76 \text { to } 30.97)\end{array}$ & $<0.001$ \\
\hline Allergic (n, \%) & $36(80)$ & $28(83.35)$ & $>0.99$ \\
\hline Duration of rhinitis (months)* & $\begin{array}{l}47.68 \pm 30.36 \\
\quad(6 \text { to } 106)\end{array}$ & $\begin{array}{l}68.12 \pm 50.01 \\
(9 \text { to } 167)\end{array}$ & 0.19 \\
\hline Percentage of life affected $(\%)^{*}$ & $\begin{array}{c}39.15 \pm 24.18 \\
(6.67 \text { to } 87.88)\end{array}$ & $\begin{array}{c}40.20 \pm 29.55 \\
(4.76 \text { to } 92)\end{array}$ & 0.92 \\
\hline Baseline PNIF (Z-score)* & $\begin{array}{c}-1.66 \pm 0.65 \\
(-2.87 \text { to } 0.59)\end{array}$ & $\begin{array}{c}-3.03 \pm 0.76 \\
(-4.70 \text { to }-1.81)\end{array}$ & $<0.001$ \\
\hline PNIF post-VC (Z-score) ${ }^{*}$ & $\begin{array}{c}-1.25 \pm 0.60 \\
(-2.89 \text { to } 0.01)\end{array}$ & $\begin{array}{c}-2.41 \pm 0.85 \\
(-3.97 \text { to }-0.62)\end{array}$ & $<0.001$ \\
\hline Baseline NO-VAS (pre-VC)* & $\begin{array}{c}4.45 \pm 2.40 \\
(0 \text { to } 10)\end{array}$ & $\begin{array}{c}4.66 \pm 2.22 \\
(1 \text { to } 9)\end{array}$ & 0.76 \\
\hline NO-VAS post-VC* & $\begin{array}{l}2.59 \pm 2.03 \\
\quad(0 \text { to } 9)\end{array}$ & $\begin{array}{l}2.64 \pm 1.73 \\
\quad(0 \text { to } 6)\end{array}$ & 0.70 \\
\hline NOSE scale* & $\begin{array}{l}48.11 \pm 23.73 \\
\quad(5 \text { to } 100)\end{array}$ & $\begin{array}{c}61.96 \pm 17.97 \\
(10 \text { to } 95)\end{array}$ & 0.01 \\
\hline
\end{tabular}

PNIF: peak nasal inspiratory flow, VC: vasoconstrictor, NO-VAS: nasal obstruction visual analog scale,

NOSE: Nasal Obstruction Symptom Evaluation.

${ }^{*}$ Data are described as mean, standard deviation, and range. 
FIGURE 2. Correlation between baseline measurements of nasal obstruction pre-vasoconstrictor administration based on visual analog scale and Z-score of peak nasal inspiratory flow in patients with chronic rhinitis

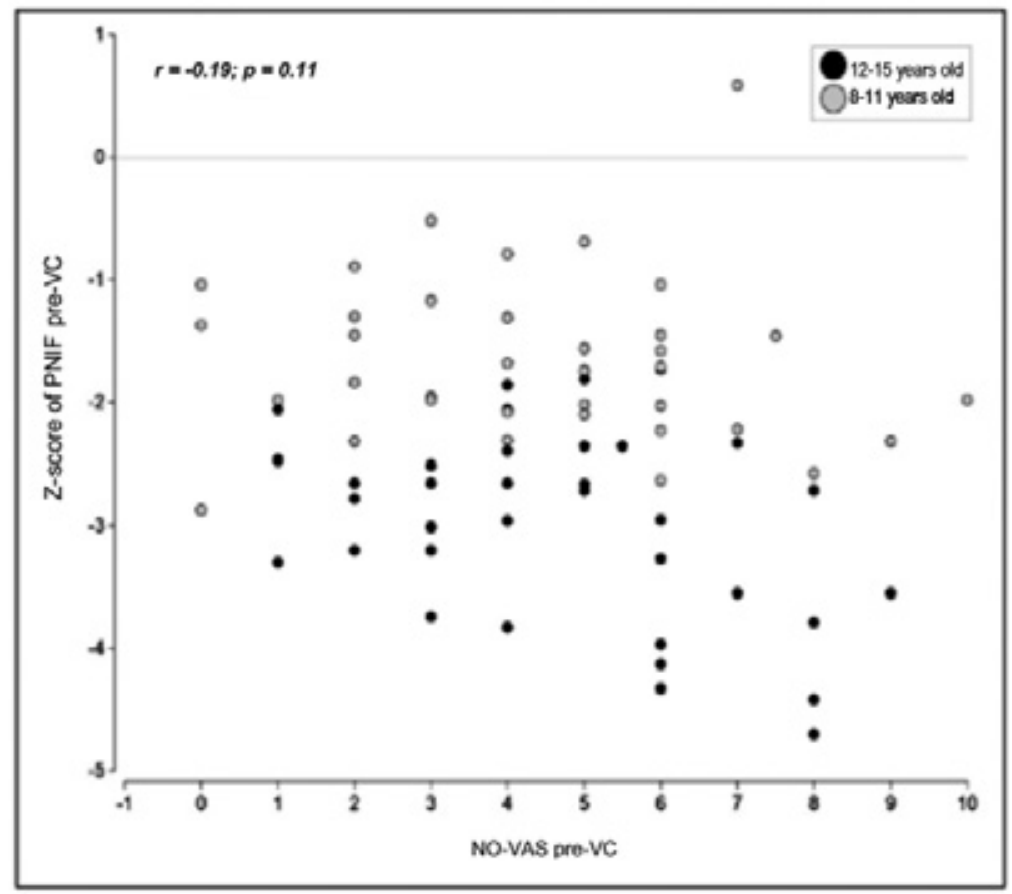

NO-VAS: nasal obstruction visual analog scale, VC: vasoconstrictor; PNIF: peak nasal inspiratory flow.

FIGURE 3. Correlation between measurements of nasal obstruction post-vasoconstrictor administration based on visual analog scale and Z-score of peak nasal inspiratory flow in patients with chronic rhinitis

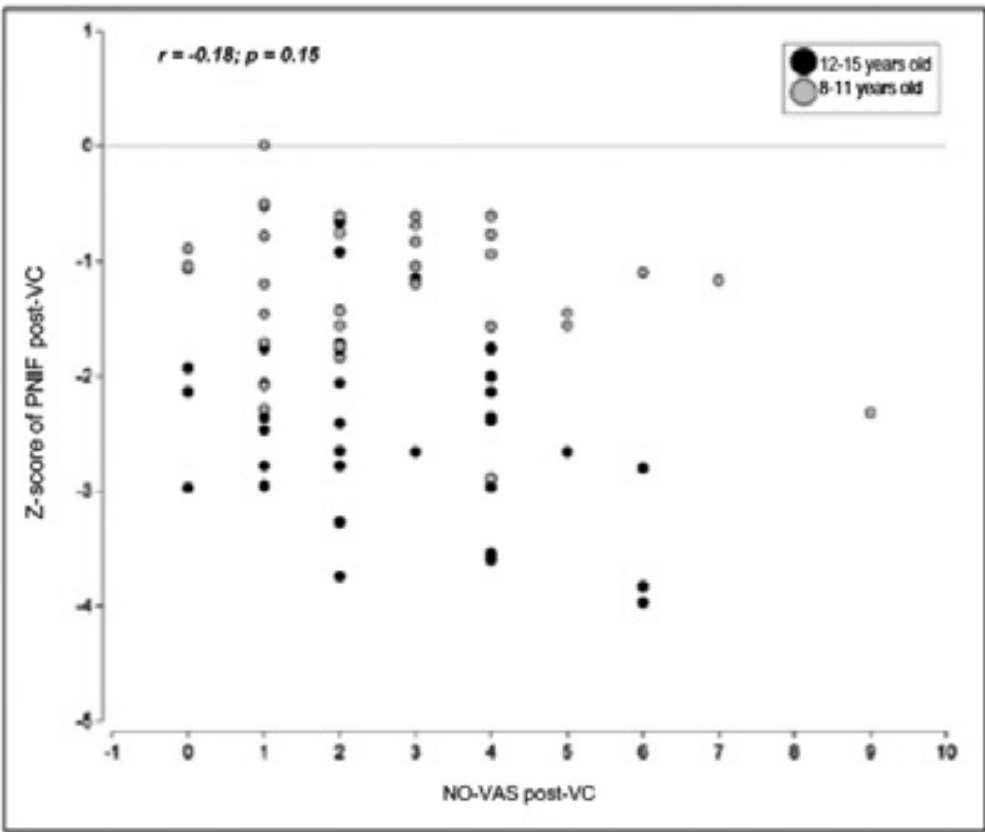

NO-VAS: nasal obstruction visual analog scale, VC: vasoconstrictor; PNIF: peak nasal inspiratory flow. 
with chronic rhinitis, research is scarce and results have been contradictory. Our study demonstrates that there is no correlation between the PNIF expressed as a Z-score (given the outcome measure dependence on age, sex, and anthropometric data) and the NOSE and VAS, at baseline and after vasoconstrictor administration, in children and adolescents with chronic rhinitis. Unlike our results, Occasi et al., ${ }^{15}$ found a significant correlation between the NOSE and AAR in children with allergic rhinitis. In addition, Sikorska-Szaflik et al., ${ }^{24}$ detected a weak, negative correlation between the PNIF and the KINDL-R (the Revised Children's Quality of Life Questionnaire) as a survey on quality of life. On their side, Mendes et al., ${ }^{14}$ established a weak correlation between the AAR and a subjective scale (0 to 10) for the assessment of NO in each nasal cavity after a nasal challenge with histamine in patients aged 7-18 years with persistent allergic rhinitis, but the overall assessment of the nose did not show the same results.

The children aged between 12 and 15 years included in our analysis showed a greater NO as measured by the PNIF, but the subjective perception established by the VAS did not differ from that in the younger group. This would demonstrate that older children have a lower perception in relative terms than those younger than 12 years. Priftis et al., ${ }^{13}$ state that the subjective perception of NO may be critically affected by the chronic nature of rhinitis. It has been speculated that a longer period suffering rhinitis may lead to a perceived "tolerance". However, there were no differences in the duration of disease or the percentage of life affected by rhinitis based on the age of our study patients, so this hypothesis for our findings could not be confirmed.

Our observations are not consistent with a recent publication that demonstrated that children aged 6 to 9 years had a lower perception of $\mathrm{NO}$ than children older than 12 years, who, in turn, overestimated NO. ${ }^{15}$ Most likely, such discrepancies may be explained by the different methods used to assess nasal resistance (AAR versus PNIF) and those authors used the NOSE, whereas our study used the VAS to assess the subjective perception of NO at the same time the PNIF was performed.

A major objective for future research may be to establish to what extent the different perceptions

FIGURE 4. Analysis of differences in Z-scores of peak nasal inspiratory flow (A) and in the baseline perception of nasal obstruction pre-vasoconstrictor administration $(B)$ in patients with chronic rhinitis by age group
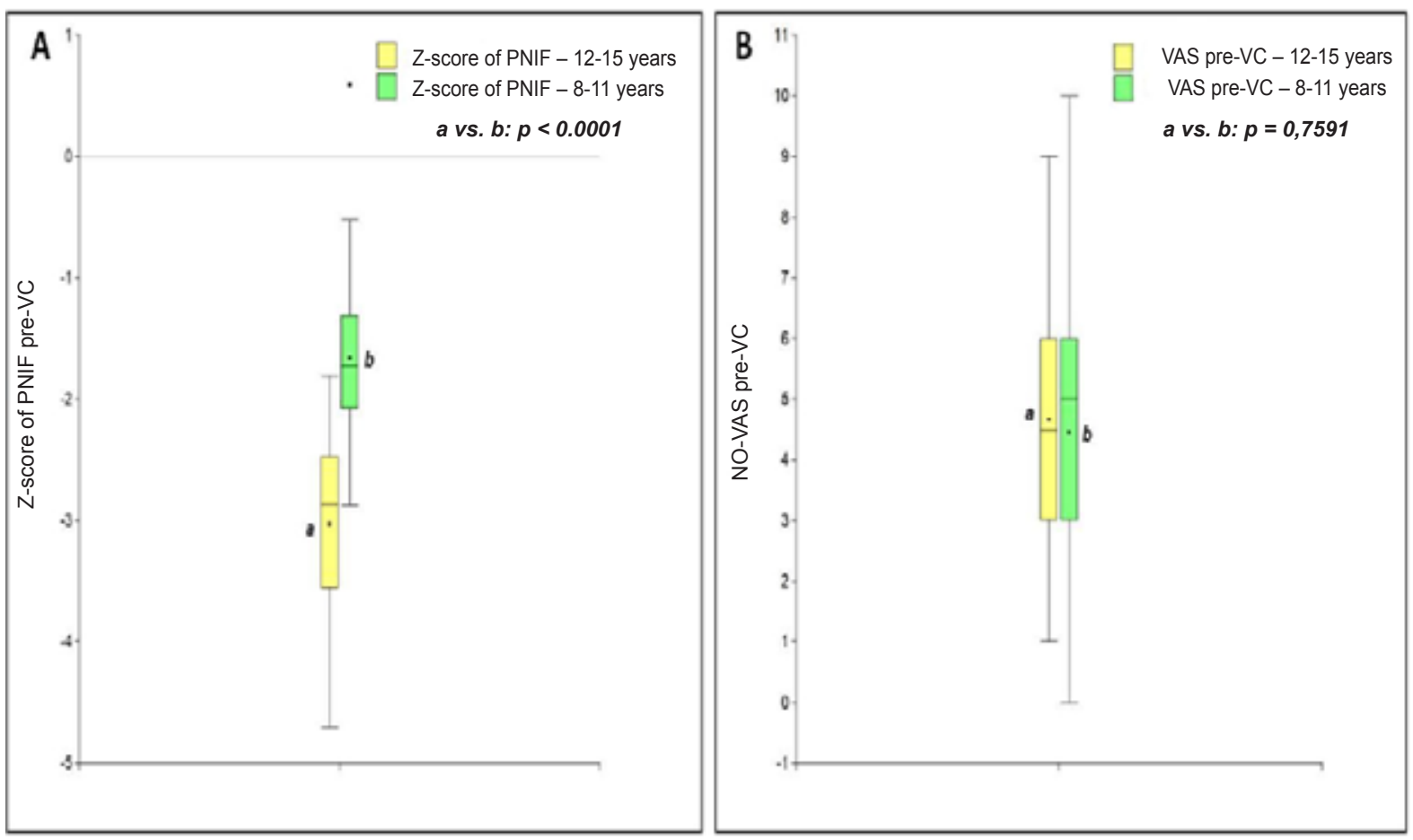
observed in our patients may be attributed to anatomical, psychosocial or cultural factors or hormonal effects.

The lack of correlation between the subjective NO scales and the PNIF used in our analysis may be because the nasal valve region is the main determinant of airflow resistance, whereas the sensation of NO may be related to congestion in other upper areas of the nose, such as the ethmoid region. ${ }^{4,25}$ Another reason may be the fact that the scales were not accurate and had not been validated. The VAS has evident limitations because it is a non-specific scale applicable to symptoms beyond NO, including pain or cough. However, it is considered valid for its clinical implementation. ${ }^{4}$ The NOSE scale is more specific to $\mathrm{NO}$ and has been validated in the Spanish language for Spain, but there is no transcultural adaptation to Argentine Spanish language, which may be deemed a weakness of this study. ${ }^{18}$ Still, we did not demonstrate a correlation between the NOSE and VAS and the PNIF values, so our study patients were not able to adequately assess the extent of NO based on both scales.

NO perception depends on several factors, such as the size of the nasal cavities, and other variables that affect nasal airflow, such as thermal and pressure receptors and the presence of nasal discharge. ${ }^{20,26}$ Therefore, we believe that subjective outcome measures should be supplemented with objective NO measurements such as the PNIF, assuming that NO perception is multidimensional. ${ }^{20}$

A strength of our study is that it demonstrated the need for an objective NO measurement beyond the subjective description of patients with rhinitis. In addition, we focused on the transformation of PNIF values into a Z-score given the variability shown by age and sex.

A potential limitation is that PNIF values obtained in our patients were referred to normal value tables that corresponded to a different population because there are no reference values available in our setting. Lastly, we believe that NO measurement may be more accurate if methods used estimated nasal resistance, such as the AAR, and not just airflow, such as the PNIF, which was used in our study.

\section{CONCLUSIONS}

Our study did not demonstrate a correlation between the subjective NO scores and the PNIF in children and adolescents with chronic rhinitis. Older children showed a lower perception of nasal blockage than younger ones. These findings suggest that subjective clinical scales to assess NO cannot replace the objective measurement using the PNIF in children and adolescents with rhinitis.

\section{REFERENCES}

1. Canonica GW, Bousquet J, Mullol J, Scadding GK, et al. A survey of the burden of allergic rhinitis in Europe. Allergy. 2007; 62 (Suppl 85):17-25.

2. Ottaviano G, Fokkens WJ. Measurements of nasal airflow and patency: a critical review with emphasis on the use of peak nasal inspiratory flow in daily practice. Allergy. 2016; 71(2):162-74.

3. AugéJ, Vent J, Agache I, Airaksinen L, et al. EAACIPosition paper on the standardization of nasal allergen challenges. Allergy. 2018; 73(8):1597-608.

4. Valero A, Navarro AM, delCuvillo A, Alobid I, et al. Position paper on nasal obstruction: Evaluation and treatment. $J$ Investig Allergol Clin Immunol. 2018; 28(2):67-90.

5. Bousquet PJ, Combescure C, Neukirch F, Klossek JM, et al. Visual analog scales can assess the severity of rhinitis graded according to ARIA guidelines. Allergy. 2007; 62(4):367-72.

6. Lara-Sánchez H, Álvarez Nuño C, Gil-Carcedo Sañudo E, Mayo Iscar A, et al. Evaluación de la obstrucción nasal mediante rinomanometría y escalas subjetivas y medición del éxito terapéutico médico y quirúrgico. Acta Otorrinolaringol Esp. 2017; 68(3):145-50.

7. Teixeira RU, Zappelini CE, Alves FS, da Costa EA. Peak nasal inspiratory flow evaluation as an objective method of measuring nasal airflow. Braz J Otorhinolaryngol. 2011; 77(4):473-80.

8. Mo S, Gupta SS, Stroud A, Strazdins E, et al. Nasal peak inspiratory flow in healthy and obstructed patients: systematic review and meta-analysis. Laryngoscope. 2021; 131(2):260-7.

9. Yepes-Nuñez JJ, Bartra J, Muñoz-Cano R, Sánchez-López J, et al. Assessment of nasal obstruction: correlation between subjective and objective techniques. Allergol Immunopathol (Madr). 2013; 41(6):397-401.

10. Lam DJ, James KT, Weaver EM. Comparison of anatomic, physiological, and subjective measures of the nasal airway. Am J Rhinol. 2006; 20(5):463-70.

11. Ciprandi G, Mora F, Cassano M, Gallina AM, et al. Visual analog scale(VAS) and nasal obstruction in persistent allergic rhinitis. Otolaryngol Head Neck Surg. 2009; 141(4):527-9.

12. Ottaviano G, Pendolino AL, Nardello E, Maculan P, et al. Peak nasal inspiratory flow measurement and visual analogue scale in a large adult population. Clin Otolaryngol. 2019; 44(4):541-8.

13. Priftis KN, Drigopoulos K, Sakalidou A, Triga M, et al. Subjective and objective nasal obstruction assessment in children with chronic rhinitis. Int J Pediatr Otorhinolaryngol. 2006; 70(3):501-5.

14. Mendes AI, Wandalsen GF, SoléD. Objective and subjective assessments of nasal obstruction in children and adolescents with allergic rhinitis. J Pediatr (Rio J). 2012; 88(5):389-95.

15. Occasi F, Duse M, Vittori T, Rugiano A, et al. Primary school children often underestimate their nasal obstruction. Rhinology. 2016; 54(2):164-9.

16. Bousquet J, Khaltaev N, Cruz AA, Denburg J, et al. Allergic Rhinitis and its Impact on Asthma (ARIA) 2008 update (in collaboration with the World Health Organization, GA(2) LEN and AllerGen). Allergy. 2008; 63 Suppl 86:8-160.

17. Eigenmann PA, Atanaskovic-Markovic M, O'B Hourihane J, Lack G, et al. Testing children for allergies: why, how, 
who and when. An updated statement of the European Academy of Allergy and Clinical Immunology (EAACI) Section on Pediatrics and the EAACI-Clemens von Pirquet Foundation. Pediatr Allergy Immunol. 2013; 24(2):195-209.

18. Larrosa F, Roura J, Dura MJ, Guirao M, et al. Adaptation and validation of the Spanish version of the Nasal Obstruction Symptom Evaluation (NOSE) Scale. Rhinology. 2015; 53(2):176-80.

19. Papachristou A, Bourli E, Aivazi D, Futzila E, et al. Normal peak nasal inspiratory flow rate values in Greek children and adolescents. Hippokratia. 2008; 12(2):94-7.

20. Kjaergaard T, Cvancarova M, Steinsvag SK. Nasal congestion index: A measure for nasal obstruction. Laryngoscope. 2009; 119(8):1628-32.

21. Di Rienzo JA, Casanoves F, Balzarini MG, González L, et al. InfoStat. Grupo InfoStat, FCA, Universidad Nacional de Córdoba; 2013. [Accessed on: March 11 $1^{\text {th }}, 2021$ ]. Available at: http:/ / www.infostat.com.ar
22. Mangeaud A, Elías Panigo DH. R-Medic. Un programa de análisis estadísticos sencillo e intuitivo. Methodo. 2018; 3(1):18-22.

23. Everhart RS, Kopel SJ, Esteban CA, McQuaid EL, et al. Allergic rhinitis quality of life in urban children with asthma. Ann Allergy Asthma Immunol. 2014; 112(4):365-70.

24. Sikorska-Szaflik H, Sozanska B. Peaknasal inspiratory flow in children with allergic rhinitis. Is it related to the quality of life? Allergol Immunopathol (Madr). 2020; 48(2):187-93.

25. Nathan RA, Eccles R, Howarth $\mathrm{PH}$, Steinsvåg SK, et al. Objective monitoring of nasal patency and nasal physiology in rhinitis. J Allergy Clin Immunol. 2005; 115(3Suppl1):S44259.

26. Thorstensen WM, Sue-Chu M, Bugten V, Cvancarova M, et al. The determining factors of peak nasal inspiratory flow and perception of nasal airflow in asthmatics. Rhinology. 2014; 52(4):348-54. 